\title{
Pelvic Peritoneum
}

National Cancer Institute

\section{Source}

National Cancer Institute. Pelvic Peritoneum. NCI Thesaurus. Code C159344.

A membranous lining of the pelvic organs. 